PERSPECTIVE

\title{
Bricks and Morals-Hospital Buildings, Do No Harm
}

\author{
Diana C. Anderson, MD, M.Arch \\ American College of Healthcare Architects; Fellow, Harvard Medical School Center for Bioethics, Boston, MA, USA.
}

The volume and rigor of evidence-based design have increasingly grown over the last three decades since the field's inception, supporting research-based designs to improve patient outcomes. This movement of using evidence from engineering and the hard sciences is not necessarily new, but design-based health research launched with the demonstration that post-operative patients with window views towards nature versus a brick wall yielded shorter lengths of hospital stay and less analgesia use, promoting subsequent investigations and guideline development. Architects continue to base healthcare design decisions on credible research, with a recent shift in physician involvement in the design process by introducing clinicians to design-thinking methodologies. In parallel, architects are becoming familiar with research-based practice, allowing for further rigor and clinical partnership. This cross-pollination of fields could benefit from further discussion surrounding the ethics of hospital architecture as applied to current building codes and guidelines. Historical precedents where the building was used as a form of treatment can inform future concepts of ethical design practice when applied to current population health challenges, such as design for dementia care. While architecture itself does not necessarily provide a cure, good design can act as a preventative tool and enhance overall quality of care.

KEY WORDS: Healthcare design; Evidence-based design; Architecture; Ethics; Hospital.

J Gen Intern Med 34(2):312-6

DOI: $10.1007 / \mathrm{s} 11606-018-4707-0$

(c) Society of General Internal Medicine 2018

66】 f every prisoner has a window, then every patient should have one too," my patient whispered, tears streaming down his face as the sky came into view for the first time in weeks. He had just left the intensive care unit, where half the rooms have no windows. What are the responsibilities of architects and clinicians towards ensuring the hospital building itself does no harm?

The ethics of hospital architecture is an area with much potential for discussion. Fundamental ethical principles which might apply within a healthcare design framework include respecting autonomy of other persons, beneficence or bringing about good in our actions, nonmaleficence or not intending to harm, and justice, or treating all people equally, fairly, and

Published online October 25, 2018 impartially. In medical ethics, the physician's guiding maxim of "First, do no harm," can be considered important within healthcare architecture, ensuring good design strategies which do good (beneficence) are applied. There are also lessons to be learned from historic designs where the healthcare building itself was used as a form of treatment.

The impact of space design on our sense of well-being is well documented. A 1984 study launched the field of Evidence-Based Design (EBD), demonstrating that postoperative patients with a view of nature versus a brick wall required less analgesia and had shorter lengths of stay. ${ }^{1} \mathrm{~A}$ subsequent meta-analysis supports single-patient rooms for infection control, nature views for lowering stress, and daylight for regulating circadian rhythms, considered important in delirium prevention. ${ }^{2}$ Evidence-Based Design combines the architect's imagination, creativity, and judgment by providing empirical data on design elements. ${ }^{3}$

Analogous to the medical profession, architects have ethical and professional responsibilities to protect the health, safety, and welfare of others. The American Institute of Architects' Code of Ethics and Professional Conduct states that members should uphold human rights in all their professional endeavors. ${ }^{4}$ Architects, like doctors, take an oath, to serve and protect the public good, aiming to design for a more beautiful world. In hospital design, the architect's main goal is to transform the foreign and hostile into a place of care and healing.

Architects face ethical choices with healthcare projects: How do hospital designs emphasize patient well-being? How can we acknowledge patient vulnerability and family stress associated with hospitalization? To what extent should nonmedical needs of families and visitors factor into specific design decisions? These questions can be better addressed through a new cross-pollination of the design and healthcare fields.

Clinical involvement in the design process can help strengthen and inform ethical design principles. Clinicians have expressed interest in incorporating design into their practice. Jon Fricchione, a University of Massachusetts medical student, notes his dual interest: "I've often dreamed of having the opportunity to directly care for patients and design products or spaces that are aimed at easing the state of being sick." To address this growing need for exchange between medical professionals with interests in design, Clinicians for Design (CfD), a non-profit international network of clinicians and scientists, seeks to unite these professionals across academia 
and design practice. Its mission is to advance the interface between healthcare and design through research, education, and policy development. ${ }^{5}$

Good design has the potential to not only promote healing and improve care delivery, but be cost saving as well. The 2004 Fable Hospital, ${ }^{6}$ and an updated version (Fable 2.0) created in $2011,{ }^{7}$ devised a composite model of recently built or renovated hospitals that implemented design based on evidence. The conservative financial estimate demonstrated that Fable's impact would add US\$12 million to construction costs by fully implementing EBD elements, earning back the added investment in one year through operational cost savings (examples include reduced patient falls, prevention of iatrogenic infections, avoiding medical errors, room transfers, and nursing turnover). For Fable 2.0, the payback period estimate was within three years. ${ }^{3}$ Above all, the physical environment can comfort patients, strengthening their physical and emotional condition, providing hope, and alleviating fear.

While architecture can be a health-promoting feature, space design can also be potentially harmful. Poor healthcare design can cause distress to patients, families, and staff. Many hospital facilities are not places that encourage healing; constant noise, dark or monochromatic color schemes, and unwelcoming spaces for families to stay with loved ones can further intensify stress. ${ }^{3}$ The documented harmful effects of poorly planned spaces, such as falls, infections, noise, and even medical errors highlight an increasing shift in health design strategies. ${ }^{2}$ The benefits of clinicians and ethicists being part of the design process going forward can be reinforced with historical precedents and upcoming trends.

While hospital architecture and medical practice have progressed alongside each other throughout history, they have rarely converged, and any convergence is relatively recent. The 1800s asylum set a precedent for the building as treatment. It was generally felt that no treatment could take place unless patients were removed from their home environment.
Although the ethical principles of patient autonomy and personal freedom are routinely set aside by this type of architecture, the ethics of psychiatric facility design are firmly rooted in beneficence. In 1854, Thomas Story Kirkbride, MD, changed the approach to mental health architecture in the USA, emphasizing the need for the moral treatment of the mentally ill through the incorporation of fresh air, ventilation, sunlight, and land. This layout became known as "The Kirkbride Plan" and influenced dozens of hospitals for more than 50 years $^{8}$ (Fig. 1).

The tuberculosis sanatoria built in the nineteenth and early twentieth centuries further illustrates hospital design as a contributing factor in treatment, planned to give patients access to nature, helping their recovery and preventing the spread of disease. The Paimio Sanatorium in Finland, designed by architect Alvar Aalto, is now a world heritage site. "The cure" was mandatory time each afternoon on outdoor terraces as fresh air was the only known therapy preceding the era of antibiotics. $^{9}$

While design cannot necessarily treat disease, it can be an important tool in preventative and therapeutic care strategies, encompassing ethical principles such as autonomy, beneficence, and nonmaleficence. Evidence-based design practice has inspired the emergence of modern day models for dementia care to promote autonomy. Research connecting architecture with neuroscience is increasing ${ }^{10}$ and has shown an overlap between the brain regions affected in the early stages of Alzheimer's and the areas important for spatial navigation, including the entorhinal cortex of the temporal lobe. ${ }^{11}$ By collaboratively researching landmarks and cognitive mapping, design solutions have the capability to combat confusion and spatial disorientation for people with dementia. ${ }^{12}$

An example of neuro-architectural research translated into current design practice is De Hogeweyk, a "dementia village" in the Netherlands, which promotes permissive wandering. Residents are free to visit amenities such as shops, a café,

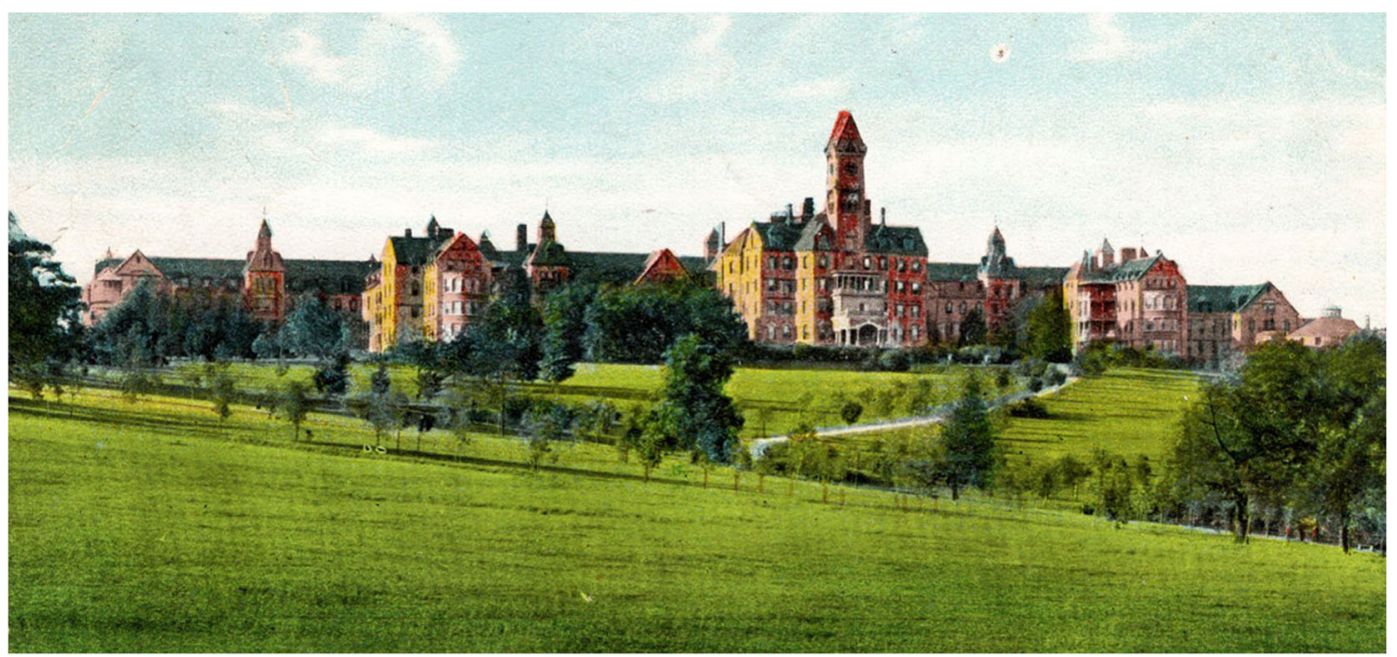

Figure 1 Kirkbride Hospitals were built at many locations in the Midwest and Eastern USA, emphasizing the positive effects of natural sunlight and air available in a country setting. A number of these facilities have been demolished including the one illustrated here: The Bloomingdale Asylum in Massachusetts (Image Credit: John Michael Currie, FAIA, FRSPH). 


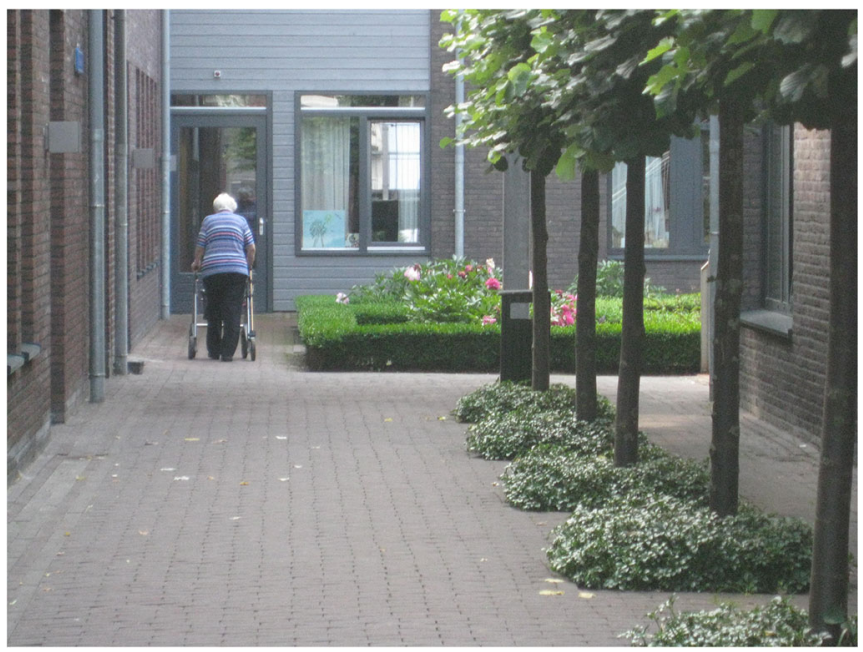

Figure 2 The De Hogeweyk dementia village in the Netherlands expresses the notions of freedom of movement and autonomy within a neighborhood setting rich with nature (Image Credit: Ray Pradinuk, Principal Architect, Stantec).

and pub. Staff report decreased agitation and medication use. More common in dementia units is the building itself acting as a restraint by concealing exit doors. Dark floor patterns in front of doors and elevators, perceived as a hole or void by some with cognitive impairment, can induce fear of leaving. ${ }^{13} \mathrm{Al}$ though freedom of movement and meaningful activity within village settings are preferred, these are not universally adopted design strategies (Fig. 2).

While architects and clinicians now focus on specialty designs for various patient populations, such as the recent shift towards geriatric emergency departments, a Universal Design approach throughout all healthcare spaces presents an alternate solution. Universal Design addresses the ethical concept of justice by providing an inclusive environment for people of all ages, sizes, abilities, and disabilities - rather than designing exclusively for a distinct set of needs. ${ }^{14}$ The premise being that the conditions that support a person with dementia-for example a calm, coherent, orientating, and gently stimulating environment - can be good for all of us. ${ }^{13}$ Pediatric spaces are planned to be colorful, immersive, and mobility promoting, but could we (and should we) apply these same design standards to our adult and geriatric design guidelines?

Although healthy design for various building types is a growing topic, whereby natural light and ventilation are considered fundamental for those incarcerated, not all patients have window access. Healthcare architects believed there was always justification for windows in patient rooms and noted the eventual prohibition of patient rooms without windows for overnight stays in 2010 building codes. ${ }^{15}$ This applies for new construction and renovation projects. Older existing facilities, such as the intensive care unit mentioned in the first paragraph, are exempt.

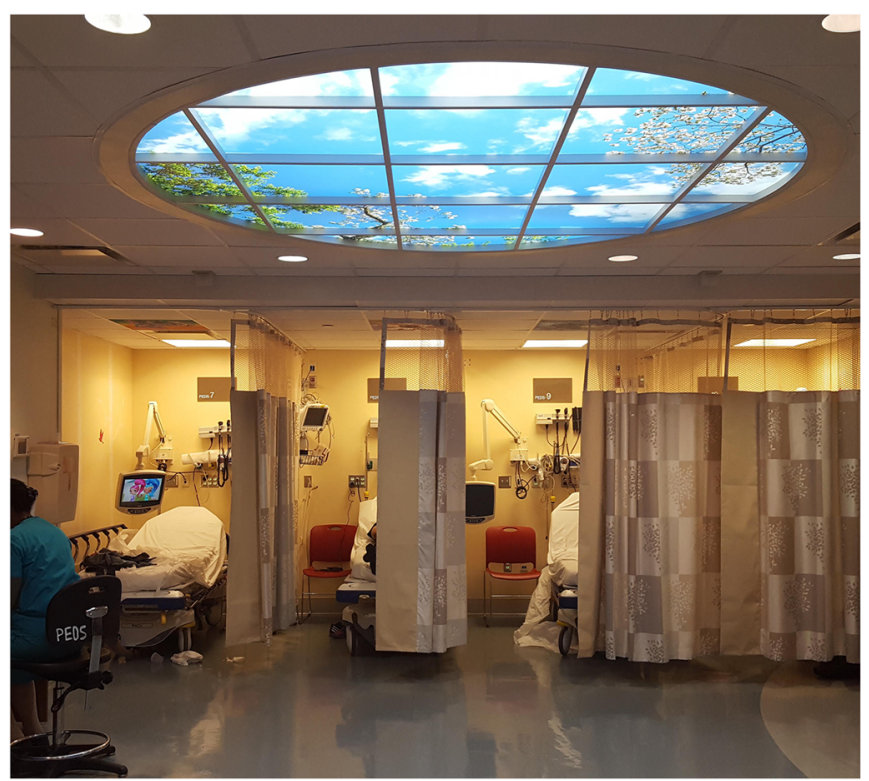

Figure 3 The Mount Sinai Health System emergency department, New York City, demonstrates an example of a virtual ceiling as a solution to existing windowless spaces (Image credit: Diana Anderson, MD, ACHA). 


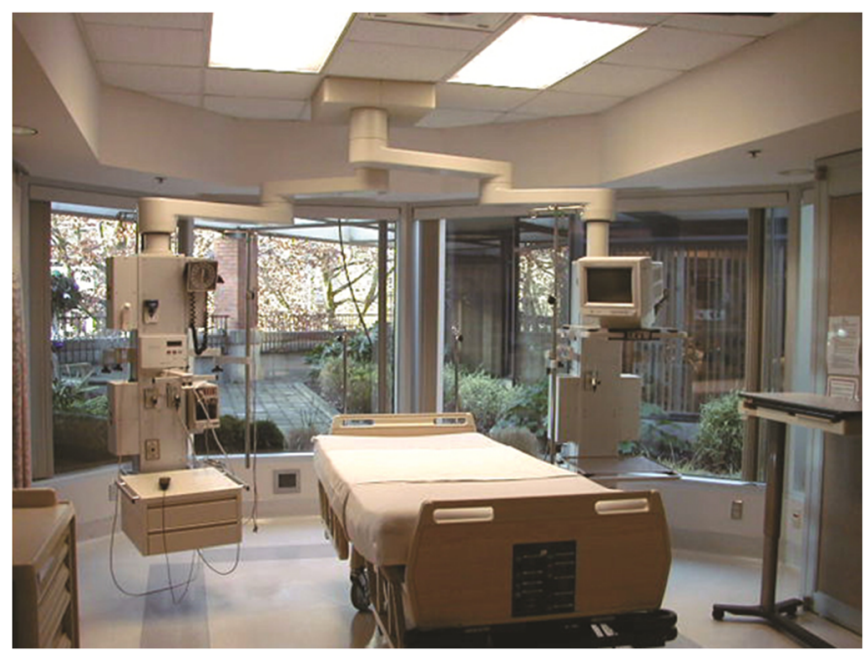

Figure 4 Legacy Good Samaritan Intensive Care Unit (ICU), in Portland, Oregon, allows critically ill patients in their beds direct outdoor access onto a terrace space if desired (Image credit: D. Kirk Hamilton, PhD, FAIA, FACHA, FCCM).

While it may be difficult to enact windows in existing spaces, design solutions exist, for example the installation of virtual windows which simulate day-night lighting patterns and circadian rhythms (Fig. 3). In oncology centers, art interventions have been shown to have a positive influence on health-related quality of life and patients' experiences. ${ }^{16}$ When asked to envision the future of the intensive care unit, physicians imagine gardens accessible to patients by the year $2050 .{ }^{17}$ How ironic to consider that designs included nature hundreds of years ago! With the advent of Evidence-Based Design, the importance of nature is being emphasized once again (Fig. 4).

How do hospital designs emphasize the well-being for those caring for patients? Clinical staff spaces have no minimum requirements for windows and only minimal standards for architects to provide respite areas and compassionate spaces for emotional expression. In Europe, by law, the work stations of employees must be within a few meters of a window and daylight. ${ }^{18}$ With rising rates of clinician burnout, ${ }^{19}$ the physical environment in promoting wellness for healthcare providers should be part of the solution. The design of "reset rooms" where physicians can go for a few moments of respite during busy or stressful moments is now being explored. ${ }^{20}$ Architecture can support the caregivers' activities, greatly expanding their power to heal. The total cost of burnout among Canadian physicians was estimated at more than $\$ 200$ million; and in the USA replacement costs are estimated to be at least $\$ 25,000$ for each primary care physician, likely higher for critical care clinicians. ${ }^{21}$ In past years, the design of the "doctor's lounge" illustrates a place where collegial relationships flourish, but today this model is almost nonexistent. ${ }^{22}$ With larger multidisciplinary healthcare teams caring for patients with increasingly complex co-morbidities, where is the new hub of activity where relationships will have a chance to thrive? Architects now focus on space design to foster face-to-face interactions, building on a parallel strategy in science whereby up to $80 \%$ of breakthroughs occur outside the laboratory environment in social settings. ${ }^{23}$
Looking ahead, architecture is in the early stages of integrating informatics into the design process, and the development of interactive environments is on the horizon. Virtual reality is already being studied to create different contexts for patients, allowing them to walk through calming locations, with the hopes of decreasing delirium and post-intensive care syndrome. ${ }^{24}$ Focusing on design to increase patient mobility through better use of hallways and alternatives to bed rest is also on current drawing boards; there is often no therapeutic value to strict bed rest, leading to muscle atrophy and overall deconditioning. ${ }^{25}$ For some, in the absence of a medical cure or transformative treatments, design might supersede drugs.

As an architect and physician, I believe the designs of our healthcare buildings are as much of an ethical construct as the care we provide patients. Yet, despite knowing how to design better hospitals, building them is still a challenge. Because hospitals exist for a long time and are expensive to construct and to operate, it is vital to use the abundant, available empirical evidence to guide design. Providing health-promoting space to all patients and healthcare staff may mean some upgrades are required, but these may in fact be economical and minimally invasive.

Although architects have moved beyond traditional bricks and mortar to research-based practice, implementing a clinically and ethically informed translational design process could ensure our hospital buildings harm less, and heal more. While architecture itself does not necessarily provide a cure, hospital design can be a tool for healing and enhance the quality of care.

Corresponding Author: Diana C. Anderson, MD, M.Arch; American College of Healthcare Architects; Fellow, Harvard Medical School Center for Bioethics, 4 Longfellow Place 1604, Boston, MA 02114, USA (e-mail: diana.anderson@dochitect.com). 


\section{Compliance with Ethical Standards:}

Conflict of Interest: The author declares that she does not have a conflict of interest.

\section{REFERENCES}

1. Ulrich RS. View through a window may influence recovery from surgery. Science. 1984;224(4647):420-1.

2. Ulrich RS, Zimring C, Zhu X, DuBose J, Seo HB, Choi YS, et al. A review of the research literature on evidence-based healthcare design. HERD. 2008;1(3):61-125.

3. Berry LL, Hamilton DK. How to build a better, safer, more welcoming hospital. The Conversation.2018.

4. American Institute of Architects. American Institute of Architects' 2017 Code of Ethics and Professional Conduct. 2017.

5. Clinicians for Design. Clinicians for Design - Vision and Mission. 2017. www.cliniciansfordesign.com.

6. Berry LL, Parker D, Coile RC, Jr., Hamilton DK, O'Neill DD, Sadler BL. The business case for better buildings. Front Health Serv Manage. 2004;21(1):3-24.

7. Sadler BL, Berry LL, Guenther R, Hamilton DK, Hessler FA, Merritt C., et al. Fable Hospital 2.0: The Business Case for Building Better Health Care Facilities. The Hastings Centre Report. 2012;42(1):13-23.

8. Currie JM. The fourth factor: A historical perspective of architecture and medicine. Washington, DC: The American Institute of Architects Academy of Architecture for Health; 2007.

9. Anderson D. Humanizing the hospital: design lessons from a Finnish sanatorium. CMAJ. 2010;182(11):E535-7. doi:https://doi.org/10.1503/ cmaj.090075

10. The Academy of Neuroscience for Architecture. The Academy of Neuroscience for Architecture - History. http://anfarch.org/about-2/history/. 2018.

11. Wiener J. Dementia-friendly architecture: Reducing Spatial Disorientation in Dementia Care Homes. UK Research and Innovation; 2018.

12. O'Malley M, Innes A, Wiener JM. Decreasing spatial disorientation in care-home settings: How psychology can guide the development of dementia friendly design guidelines. Dementia (London). 2017;16(3):315-28. doi:https://doi.org/10.1177/1471301215591334

13. Montague J. How design is helping people with dementia find their way around. The Guardien. 2018.

14. National Diasbility Authority. Centre for Excellence in Universal Design. 2014. http://universaldesign.ie/. 2018.

15. Facilities Guidelines Institute. Guidelines for Design and Construction of Hospitals and Outpatient Facilities 2010. Chicago, IL: American Society of Healthcare Engineering of the American Hospital Association; 2010.

16. McCabe C, Roche D, Hegarty F, McCann S. 'Open Window': a randomized trial of the effect of new media art using a virtual window on quality of life in patients' experiencing stem cell transplantation. Psychooncology. 2013;22(2):330-7. doi:https://doi.org/10.1002/pon. 2093

17. Vincent $\mathbf{J L}$, Slutsky AS, Gattinoni L. Intensive care medicine in 2050: the future of ICU treatments. Intensive Care Med. 2017;43(9):1401-2. doi:https://doi.org/10.1007/s00134-016-4556-4

18. Hamilton DK. Too Sick for the Window and the View? HERD. 2016;9(2):156-60. doi:https://doi.org/10.1177/1937586715617111

19. West CP, Dyrbye LN, Shanafelt TD. Physician burnout: contributors, consequences and solutions. J Intern Med. 2018;283(6):516-29. doi:https://doi.org/10.1111/joim.12752

20. Parks T. Physicians take to "reset room" to battle burnout. American Medical Association (AMA) Wire.2016.

21. Moss M, Good VS, Gozal D, Kleinpell R, Sessler CN. An Official Critical Care Societies Collaborative Statement: Burnout Syndrome in Critical Care Healthcare Professionals: A Call for Action. Crit Care Med. 2016;44(7):1414-21. doi:https://doi.org/10.1097/CCM. 0000000000001885

22. Gunderman R. What Happened to the Doctors' Lounge? The Atlantic Health. Nov 5, 2013.

23. Jen L. Genetic complement. Canadian Architect. 2006:28-33.

24. Weidenbener $\mathbf{L}$. Doctors use VR to try to reduce ICU delirium. Indianapolis Business Journal. 2018;39(14):8-9.

25. Creditor MC. Hazards of hospitalization of the elderly. Ann Intern Med. 1993; 118(3):219-23. 